\title{
Model za preučevanje izseljenskih skupnosti na kanadsko-slovenskem primeru
}

\author{
Alenka Čuš \\ Fakulteta za humanistične študije, Oddelek za slovenistiko, Univerza na Primorskem \\ Faculty of Humanities, Department for Slovene Studies, University of Primorska \\ alenkacus@gmail.com
}

V prispevku vzpostavljamo model za preučevanje izseljenskih skupnosti kot samostojne strukture na kanadsko-slovenskem primeru. $\mathrm{Z}$ dvoletnim terenskim delom in notranjim statusom raziskovanja smo skupnost opazovali po taksonomiji spremenljivk Howarda Gilesa (1977), ki določajo empirično realnost manjšinske skupnosti. Zaradi pomanjkljivosti tovrstnega pristopa $\mathrm{v}$ analizi smo se lotili vzpostavitve primernejšega modela s pomočjo literarnih študij, ki ne omogoča le opazovanja in ocene stanja skupnosti, temveč tudi na osnovi teorije udejanjanja narodnega poziva po Marcellu Potoccu (2012) dvig vitalnosti oz. krepitev slovenske narodne identitete. Model namreč omogoča aktivno udeležbo v okviru dejanj in implementacijo dodatnih dejanj, ki služijo opazovanju in urejanju le-teh glede na avtentične razmere in potrebe. Vitalnost skupnosti smo nato vnovič ocenili in primerjali s pilotsko oceno ter dokazali, da je pristop učinkovit.

Ključne besede: ocena vitalnosti, udejanjanje narodnega poziva, krepitev slovenske narodne identitete, kanadsko-slovenska izseljenska skupnost 


\section{A Research Model for Examining Diaspora Communities Applied to the Slovene-Canadian Case}

This paper presents a model for studying diaspora communities as independent structures for the Slovene-Canadian case. Using the researcher's two years of fieldwork as well as the intracommunity status of the researcher, we observed the community with the taxonomy of variables by Howard Giles (1977) that determines the empirical reality of minority communities. Due to the shortcomings of this approach in the analysis, we established a more appropriate model with the assistance of literary studies, which not only enables the monitoring and assessment of the community, but on the basis of the theory of realization of national interpellation by Marcello Potocco (2012), we are able to increase the actual vitality and strengthen the Slovene national identity. The model allows participation in the activity, not only for observing, but for implementation of additional activity as well according to the existing situations and needs of the community. The vitality of the community was re-assessed and the results compared with the pilot assessment. The comparison demonstrated that the proposed approach is effective.

Key words: vitality assessment, realization of the national interpellation, empowerment of the Slovene national identity, Slovene-Canadian diaspora community

Skupnost kanadskih Slovencev temelji na prostovoljnem delu in ohranjanju slovenske narodne identitete v kulturni komponenti. V provinci Ontario obstaja več kot 30 kanadsko-slovenskih institucij, ki so med seboj povezane s krovno organizacijo Vseslovenski kulturni Odbor/All Slovenian Cultural Committee (pogovorno VSKO) v Torontu. V južnem Ontariu za to skrbi SKON Niagara, ki je prav tako vključena v VSKO, ter slovenski župniji v Torontu (Brezmadežne s čudodelno svetinjo) in Hamiltonu (sv. Gregorija Velikega). Urška Strle (2009, 4-6) ugotavlja, da je v Sloveniji poudarek na raziskovanju Slovencev v Avstraliji in Argentini ter drastični primanjkljaj podatkov na temo kanadskih Slovencev, ki so jih v preteklosti, ne glede na povsem drugačno ozadje ciljne kulture Kanade, večinoma obravnavali kar skupaj s Slovenci v ZDA. Za osrednji predmet preučevanja si torej določimo makrosociolingvistično (institucionalno in kolektivno) delovanje ontarijskih Slovencev, in sicer za obdobje 2014-2015. Ne zanima nas le, na kakšen 
način se v skupnosti ohranja slovenska narodna identiteta, ampak predvsem sodobno stanje skupnosti ter možnosti za njeno krepitev.

Obravnave skupnosti se lotimo $\mathrm{z}$ aplikativnim pristopom ${ }^{\mathrm{I}}$ oziroma $\mathrm{z}$ metodo pragmatizma, katere jedro je po Williamu Jamesu sledenje praktičnim posledicam $(2002,214)$. Pragmatična metoda torej izvira iz sledenja strukturi realnosti in strukturi našega spoznavanja le-te $(2002,220)$, pri čemer je realnost odprta, ranljiva, nedokončana, subjekt pa nastopi, da jo konča (Šimenc 2002, 223). James pragmatizem vidi kot pogled v prihodnost, v primerjavi z racionalizmom, ki se ozira k pretekli večnosti (2002, 123). Potemtakem pragmatizem omogoča empirični pristop, ki se »obrne k stvarnosti in skladnosti, dejstvom, delovanju in moči« (James 2002, 39). Postavke za sledenje strukturi realnosti smo določili po modelu Howarda Gilesa (Nećak Lük 1998) oziroma njegovi t. i. taksonomiji strukturnih spremenljivk, ki učinkujejo na etnično-jezikovno vitalnost skupnosti in naj bi torej predstavljale neposredno empirično realnost manjšinske skupnosti. Delijo se na: statusne spremenljivke, ki kažejo izoblikovanost prestižnih skupnostnih statusov (pravni; politični; ekonomski; socialni; družbeno-zgodovinski; jezikovni); demografske spremenljivke, ki prikazujejo skupnost $\mathrm{v}$ številkah (nacionalni teritorij; koncentracija razmerja; absolutno število; naravni prirastek; mešani zakoni; imigracije; emigracije) ter institucionalno podporo (državna in/ali lastna institucionalna podpora $\mathrm{v}$ organizaciji manjšine; množična občila; vzgoja in izobraževanje; administrativne usluge; industrija; veroizpoved; kultura; stiki z matico). Giles poleg analize teh okoliščin empirične realnosti upošteva še subjektivni vidik pripadnikov. Preverja samopercepcijo manjšine v imenu članov skupnosti ter zunanjih opazovalcev oz. večine, obojih z vprašalnikom (Nećak Lük 1998, 25). Slednji Gilesov pristop za subjektivno oceno vitalnosti nadomestimo $s$ t. i. participativnim modelom, kar po Michaelu Mullerju pomeni pristop in dizajniranje $\mathrm{z}$ namenom, da se $\mathrm{v}$ procesu načrtovanja skuša aktivno vključiti vse strani sodelujočih. Tako se zagotovi, da rezultati ustrezajo potrebam skupnosti in da so zaradi tega sploh uporabni (Participatory Design 2015). Za ta model se odločimo, ker želimo, da rešitve za krepitev slovenske narodne identitete $\mathrm{v}$ prvi vrsti ustrezajo obstoječim avtentičnim razmeram ter potrebam kanadsko-slovenske skupnosti in ne perspektivi ter pravnoformalnim aktom matične Slovenije, vezanih na Slovence v izseljenstvu.

23 tednov terenskega dela med kanadskimi Slovenci v Ontariu od skupno 110 je delno financiral Javni sklad RS za razvoj kadrov in štipendije za študijski obisk Vloga literature $v$ konstrukciji naroda $\mathrm{v} 2014$. 
V letu 2013 smo začeli s pilotskim ocenjevanjem vitalnosti skupnosti. V seštevku skupne ocene vitalnosti po posamičnih kategorijah smo statusne spremenljivke kanadsko-slovenske skupnosti ocenili z oceno srednja vitalnost, institucionalno podporo z oceno srednje nizko. Zaradi pomanjkanja podatkov demografskih spremenljivk pa teh niti ni bilo mogoče oceniti (Čuš 2013), zato ugotavljamo, da po Gilesovem modelu ne moremo pripraviti ocene vitalnosti skupnosti $\mathrm{v}$ celoti. Šele $\mathrm{z}$ notranjim statusom raziskovanja smo ugotovili tudi druge pomanjkljivosti Gilesovega modela. Ta je namreč popolnoma osredotočen na formalno delovanje skupnosti, kar nas postavi v veliko zadrego pri iskanju zapisanih argumentov, ko zaradi prostovoljnega dela delovni procesi večinoma potekajo neformalno in/ali v govorjenem jeziku. Prav tako smo prišli do sklepa, da čeprav gre za model, ki je namenjen ocenjevanju vitalnosti manjšin, preveč zavzema stališča perspektive večinskega naroda oz. matične domovine. To je razvidno že iz same zastavljene postavke državna in/ali lastna institucionalna podpora $\mathrm{v}$ organizaciji manjšine. Ravno zaradi perspektive izvorne države Gilesovega modela ne moremo uporabiti za ustrezno analizo vitalnosti strukture realnosti, saj skupnost opazujemo kot samostojno in ne priključeno strukturo. To pomeni, da jo opazujemo od znotraj ter s stališča kanadsko-slovenske skupnosti in ne s perspektive izvorne ali ciljne države. Tak pristop se izkaže za zelo relevantnega, zato izbira Gilesovega modela ne zadostuje oz. ne ustreza.

Vzporednice za ohranjanje in krepitev narodne identitete iz sociolingvistike smo ugotovili v literarni zgodovini, v delu Marcella Potocca, Nacionalni imaginariji, literarni imaginariji: različice narodnega poziva $v$ literaturi in literarnih kontekstih (2012) in v udejanjanju narodnega poziva (tudi interpelacije oz. naslavljanja). Narodni poziv po Potoccu združuje imaginarno in ideologijo. Imaginarno pomeni zmožnost tvorjenja podob ali neomejen tok podob, ki je razpoložljiv za zamejitve v simbolnih odnosih in so ga skupnosti vedno skušale fiksirati. Ideologijo pa Potocco razume kot udejanjanje družbeno imaginarnega, ki teži k fiksaciji pomena (2012, 238). Po Bogdanu Lešniku narodni poziv pomenijo dejanja v praksi, saj že Althusser vidi ideologijo kot družbeno tkivo in kot najrazličnejše rituale materialne eksistence ideološkega aparata, npr. mašo v cerkvi, nepomembno nogometno tekmo $\mathrm{v}$ športnem društvu, šolski dan v neki šoli (1997, 23-25). Lešnik kot dva pogoja za posrečeno interpelacijo navaja prepoznanje dejanja in opiranje na predhodno interpelacijo (Lešnik 1997, 39-40). Potocco se v izhodišču loti vprašanja naroda in ga opredeli kot 
imaginarno, diskurzivno ter ideološko konstrukcijo, zgrajeno s pomočjo šolstva in simbolnih figur; nato pa še utemeljevitvenega mita in literarnih, družbeno-historičnih ter socioloških vidikov slovenske in kanadske literarne zgodovine (2012, 241). Kot izvor družbene identitete sprva vpelje pojem imaginarnega po Corneliusu Castoriadisu, ga poveže z ideologijo in literaturo. Nato obravnava materialne dejavnike za narodni poziv oz. udejanjanje ideološke funkcije narodne interpelacije za strukturo večinskega naroda, in sicer družbenozgodovinski razvoj, institucije in medije, literarni sistem, založniški trg ter šolski sistem (Potocco 2012).

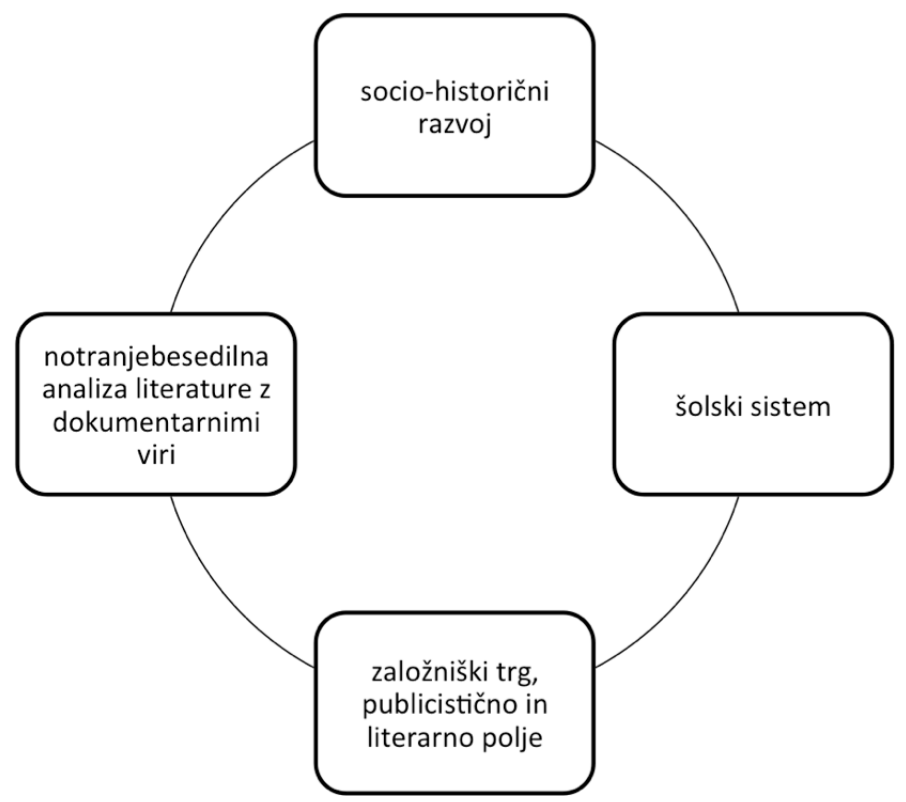

\section{Model I: Model materialnih dejavnikov udejanjanja narodnega poziva po Marcellu Potoccu (2012)}

Tovrstni dejavniki se že na prvi pogled skladajo s podobo, ki jo sicer nudi tudi že sociolingvistični pristop in Gilesov model. Ker pa se spremeni predmet preučevanja, torej, ker v ospredje stopi književnost, ravno tako pa tudi metode, se krepitev narodne identitete obravnava na drugačen način. Potemtakem ne gre samo za opazovanje in oceno vitalnosti empirične realnosti, pač pa za dejanja naslavljanja v praksi, kot pravi Lešnik. S tovrstnim pristopom ocenjujemo njeno vitalnost, poleg tega pa tudi opazujemo dejanja, krepimo obstoječa ali dodamo nova. Potoccove dejavnike si zato 
zastavimo kot področja raziskovalčevega delovanja v skupnosti; torej ne samo za opazovanje, kot bi bilo po Gilesovem modelu, ampak za področja aktivne participacije. Slednje nam omogoča tako spremljanje kot morebiti tudi apliciranje ustreznih smernic narodnega poziva za krepitev slovenske narodne identitete. Literarni pristop skratka temelji na imaginarnem in ideologiji, medtem ko sociolingvistični na empirični realnosti in instituciji. Gilesov model izseljensko skupnost opazuje s perspektive večinskega naroda oz. matične domovine, Potoccov pa znotraj in kot samostojno strukturo. Ker model po Potoccu ponuja rešitve za težave, na katere smo naleteli pri rabi Gilesovega modela, se izkaže za ustrezno rešitev v obravnavi ohranjanja ter krepitve narodne identitete, četudi gre v našem primeru za izseljensko skupnost in ne za enonacionalno večinsko strukturo $\mathrm{z}$ namenom državotvornosti, kot je to pri Potoccu. Za kanadski in slovenski primer Potocco ugotavlja, da sta izhajala iz splošne paradigme evropskega in neevropskega kulturnega nacionalizma $(2012,241)$, kar pomeni, da tip konstrukcije naroda ni utemeljen v politično-teritorialni ali državni enotnosti, ampak v principu skupnega etničnega in kulturnega izvora $(2012,37)$. Navedeno lahko velja tudi za izseljensko skupnost v sodobnem času, iz česar lahko sklepamo, da lahko njegovi dejavniki za udejanjanje narodnega poziva držijo tudi za izseljensko oz. manjšinsko skupnost.

Sčasoma se je izkazalo, da navedeno ne drži povsem in da moramo biti pri opazovanju dejavnikov v manjšinski skupnosti natančnejši. Poglavitni dejavniki so lahko v večji meri oslabljeni, narodni poziv pa se na primeru izseljenske skupnosti udejanja tudi na drugih področjih. Z empiričnim preverjanjem Potoccovega modela v sinhronem preučevanju smo potemtakem določili dejavnike, ki veljajo za udejanjanje narodnega poziva, specifično za izseljensko skupnost. $\mathrm{V}$ aplikativnem pristopu smo sodelovali v najrazličnejših dejavnostih skupnosti in ugotavljali, kje in kako se udejanja narodni poziv. Dejanja kanadsko-slovenskega primera smo torej analizirali tako predvsem na recepcijski strani na vseh področjih, na nekaterih pa tudi pri produkciji. Rezultati empiričnega pristopa se na prvi pogled ujemajo $\mathrm{z}$ ugotovitvami Potocca. Četudi gre v našem primeru za sinhrono preučevanje manjšinske skupnosti v sodobnem času, drži, da so najmočnejši dejavniki še vedno šolski sistem, literarna institucija ter družbeno-institucionalni kontekst (v diahronem preučevanju po Potoccu socio-historični razvoj). Kljub temu pa je specifično za izseljensko skupnost potrebno obrazložiti dejavnike po Potoccu ter določiti še druge, ki prav tako udejanjajo narodni poziv. Potocco za enega izmed dejavnikov določa šolski sistem, ki se je tudi 
Tabela i: Ohranjanje in krepitev narodne identitete

\begin{tabular}{|c|c|}
\hline \multicolumn{2}{|c|}{ OHRANJANJE IN KREPITEV NARODNE IDENTITETE } \\
\hline JEZIKOSLOVJE/SOCIOLINGVISTIKA & LITERARNA ZGODOVINA \\
\hline $\begin{array}{l}\text { OCENA ETNIČNO-JEZIKOVNE } \\
\text { VITALNOSTI } \\
\text { ocena vitalnosti - spremenljivke za determini- } \\
\text { ranje emp. realnosti }\end{array}$ & $\begin{array}{l}\text { UDEJANJANJE NARODNEGA POZIVA } \\
\text { ocena in dvig vitalnosti (dejanja/krepitev) }\end{array}$ \\
\hline $\begin{array}{l}\text { Taksonomija spremenljivk po Gilesovem } \\
\text { modelu, ki določajo emp. realnost: } \\
\text { - statusne (pravni, politični, ekonomski, } \\
\text { socialni, družbeno-zgodovinski, jezikovni } \\
\text { status) } \\
\text { - demografske (nacionalni teritorij, } \\
\text { koncentracija razmerja, absolutno število, } \\
\text { naravni prirastek, mešani zakoni, imigracije, } \\
\text { emigracije) } \\
\text { - institucionalna podpora (državna in/ali lastna } \\
\text { v organizaciji manjšine, množična občila, } \\
\text { vzgoja in izobraževanje, administrativne } \\
\text { usluge, industrija, religija, kultura, stiki z } \\
\text { matico) } \\
\text { (Nečak Luk 1998, 35) }\end{array}$ & $\begin{array}{l}\text { Materialni dejavniki udejanjanja narodnega po- } \\
\text { ziva v literaturi po Potoccu (2012): } \\
\text { - družbenozgodovinski razvoj; } \\
\text { - institucije in mediji } \\
\text { - založniški trg } \\
\text { - literarni sistem } \\
\text { - šolski sistem }\end{array}$ \\
\hline $\begin{array}{l}\text { + subjektivni vidik: } \\
\text { Mullerjeve postavke za participativni model: } \\
\text { identitete; delovni jezik; delovna dinamika } \\
\text { in predpozicije; razmerja in dogovori; ter } \\
\text { kolektivne akcije. } \\
\text { (Muller in Druin } 2003,12 \text { ) }\end{array}$ & \\
\hline
\end{tabular}

v izseljenski skupnosti izkazal za dejavnega in smo zato načrtno največ časa posvetili ravno šolstvu. Nadalje pa moramo dodati, da se narodni poziv na tem področju ne izraža zgolj in samo v šolstvu, torej v slovenski sobotni šoli in tečajih slovenščine kot drugega tujega jezika, pač pa tudi širše v skupnosti, v celotni sferi vzgoje in izobraževanja, saj se izvajajo in so močno zastopane še izobraževalne dejavnosti v zvezi s športom in glasbo. Pevski zbori, folklora in skavti so namreč tudi pojmovani kot institucije, ravno tako kot slovenska šola. Za primer manjšinske skupnosti potemtakem trdimo, da šele vse te institucije skupaj tvorijo izobraževalni sistem za udejanjanje narodnega poziva, in ne zgolj šolstvo. Namesto šolskega sistema kot dejavnika narodnega poziva zato določimo širše področje, vzgojo in izobraževanje. $\mathrm{V}$ določanju specifičnih dejavnikov za manjšinsko skupnost niti ne izpustimo Potoccove predpostavke za znotrajbesedilno analizo literature $\mathrm{z}$ dokumentarnimi viri, in njegove trditve, da se narodni poziv ne udejanja samo $\mathrm{z}$ literaturo kot produkti, ampak tudi vsebinsko. To je namreč zelo pomembno 
še posebej za izseljensko skupnost, saj so dokumentarni viri o kanadskih Slovencih in njihovi skupnosti pomanjkljivi, dostopni pa večinoma ravno $\mathrm{v}$ obliki umetnostnih besedil. Tako nam lahko notranjebesedilna analiza prinese veliko materiala oz. argumentov o izseljenskih okoliščinah, četudi služijo le za razumevanje socio-historičnega razvoja. Ravno zato jo predlagamo tudi v modelu dejavnikov narodnega poziva za izseljensko skupnost, a predstavlja le del celotnega dejavnika literarne institucije, saj se drugi dejavniki izkažejo kot enakovredno relevantni glede na obseg. Relevantna se zdi tudi raba jezika, saj ne obravnavamo večinskega naroda, ki ga na izvornem ozemlju povezuje en jezik. V izseljenski skupnosti se dejavniki narodnega poziva lahko udejanjajo $\mathrm{v}$ dveh jezikih, hkrati pa raba slovenščine in izbira le-te pred angleščino, ki je jezik okolja, postane sama po sebi močan materialni dejavnik. Jezik ravno tako opazujemo tudi v govorjeni in ne le zapisani obliki, kot bi obveljalo za diahrono preučevanje po Potoccovem modelu, prav tako pa tudi $\mathrm{v}$ neformalnem položaju, ne le formalnem. Izseljenska skupnost deluje $\mathrm{v}$ okviru skupnega preživljanja prostega časa njenih pripadnikov, ki je pojmovano kot njihova primarna dejavnost, ker je vezana predvsem na družinske navade, običaje in tradicije ter religiozno izročilo, in je recimo vidna $\mathrm{v}$ udeležbi kolektivnih zbiranj $\mathrm{v}$ obliki banketov s slovensko hrano in glasbo. Zato dodamo še samostojen dejavnik izven literarne institucije, ki velja specifično za izseljensko skupnost, da se intenzivno udejanja narodni poziv slovenske identitete. Sem smo uvrstili religijsko izročilo, glasbo, kulinariko, šport in gospodarstvo. Glede na kanadsko-slovenski primer v 2014 in 2015 torej določimo materialne dejavnike za udejanjanje narodnega poziva za izseljenske skupnosti v sodobnem času, in sicer: družbeno-institucionalni kontekst (socio-historični razvoj v sinhronem preučevanju); vzgoja in izobraževanje; literarna institucija - založniški trg, mediji, literarni sistem (zunaj- in znotrajbesedilna analiza); raba jezika (zapisanega/govorjenega) ter pod drugo religijsko izročilo, glasba, gospodarstvo, kulinarika, šport.

Skupnost torej krepi slovensko narodno identiteto po dolgoletnem ustaljenem prostovoljnem ritmu $\mathrm{z}$ organiziranjem kulturnih, glasbenih, športnih in cerkvenih prireditev ter aktivnosti. Te pa se z leti manjšajo na številčnosti tako produkcije kot tudi recepcije - manjša se število aktivnosti, ciljna publika oz. udejstvovanje pripadnikov, še najbolj pa se dejanja narodnega poziva obstoječih šibijo. $\mathrm{V}$ aplikativnem pristopu ravno zato nismo samo opazovali in določali dejavnikov narodnega poziva, pač pa avtentične razmere in potrebe tudi sproti analizirali. Zaradi notranjega statusa razisk- 


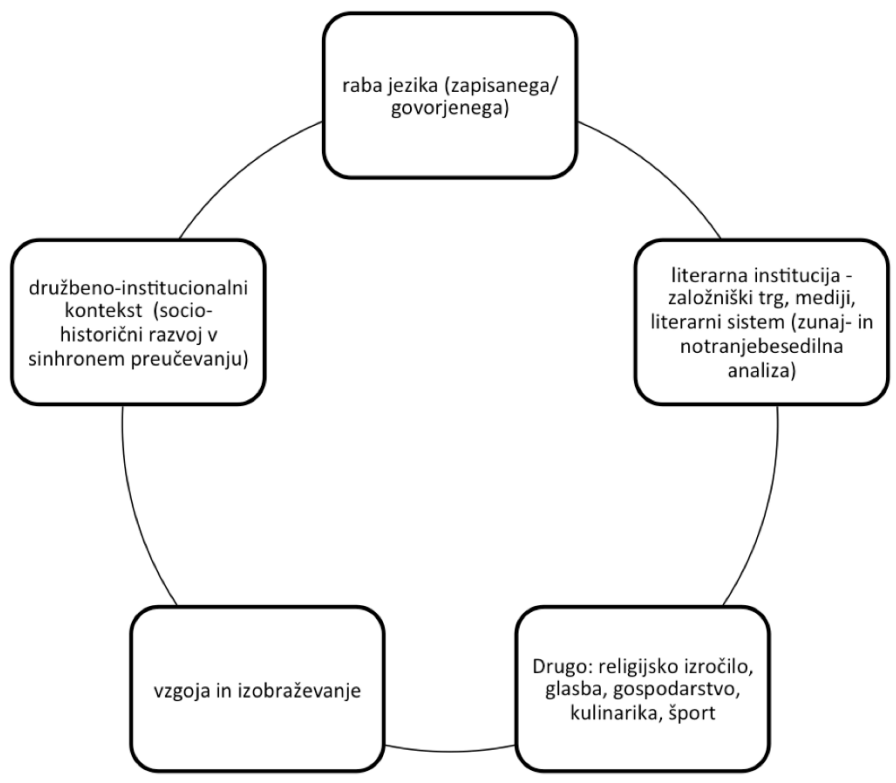

Model 2: Materialni dejavniki udejanjanja narodnega poziva v izseljenski skupnosti

ovanja pa smo sčasoma lahko še predlagali in uresničili dodatna dejanja $\mathrm{z}$ upoštevanjem participativnega modela. Najuspešnejši smo bili na področju tiskanega medija, Glasila, v 6. razredu Slovenske šole ter v spodbujanju govorjene rabe slovenskega jezika. Zagotovo pa smo vsaj z minimalnimi dejanji vplivali na vse dejavnike udejanjanja narodnega poziva. Če po obdobju terenskega dela v 2014 in 2015 znova ocenimo vitalnost skupnosti po Gilesovi taksonomiji spremenljivk zaradi natančnejšega uvida v obstoječa dejanja narodnega poziva, prav tako pa zaradi krepitve slovenske narodne identitete $\mathrm{v}$ dejavnikih predlaganega literarnega modela, dobimo takšno oceno:

Glede na to, da se v 2014 in 2015 niso spreminjali niti pravno-formalni akti, vezani na Slovence po svetu v Sloveniji, niti migracijska politika, vezana na obstoječe priseljenske skupnosti v Kanadi, ali akti skupnosti kanadsko-slovenske skupnosti, je ocena za pravni status ostala nespremenjena oz. taka, kot smo jo ocenili v pilotski oceni, ko smo posebno pozornost namenjali ravno zakonodaji (Čuš 2013). Oceno političnega statusa pa smo ocenili s kar dvema ocenama višje. Po spomladanskih volitvah 2015 v krovni VSKO, ko je po več letih predsedovanja Marjana Kolariča 
Tabela 2: Ocena vitalnosti kanadsko-slovenske skupnosti v Ontariu za 20I4-20I5

\begin{tabular}{lll}
\multicolumn{1}{c}{ Statusne spremenljivke } & Demografske spremenljivke & \multicolumn{1}{c}{ Institucionalna podpora } \\
\hline $\begin{array}{l}\text { Pravni status } \\
\text { S S }\end{array}$ & $\begin{array}{l}\text { Skupnostni teritorij } \\
\text { SV SV }\end{array}$ & $\begin{array}{l}\text { Lastna v organizaciji manjšine } \\
\text { S SV }\end{array}$ \\
\hline $\begin{array}{l}\text { Politični status } \\
\text { SN SV }\end{array}$ & Koncentracija razmerja & $\begin{array}{l}\text { Množična občila } \\
\text { SN SV }\end{array}$ \\
\hline Ekonomski status & $/$ & Vzgoja in izobraževanje SN SV \\
S SV & Absolutno število & \\
\hline Socialni status & $/$ & Administrativne usluge SN SN \\
S & Naravni prirastek & Industrija \\
\hline $\begin{array}{l}\text { Družbeno zgodovinski status } \\
\text { S S }\end{array}$ & Mešani zakoni & N S \\
\hline Jezikovni status: & $/$ & Religija \\
znotraj skupnosti N S & Imigracije, emigracije & S S \\
zunaj skupnosti N N & $/$ & Kultura \\
\hline & & S S \\
\hline S S-SV & & Stiki z matico \\
& & S SV \\
\hline
\end{tabular}

Legenda: $\mathrm{N}$ = nizka, $\mathrm{SN}=$ srednje nizka, $\mathrm{S}=$ srednja, $\mathrm{SV}=$ srednje visoka, $\mathrm{V}=$ visoka vitalnost

Pilotska ocena $=$ prva postavka; ocena vitalnosti $=$ druga postavka

zamenjal Milan Vinčec, je namreč skupnost tako pridobila dodatnega političnega predstavnika. Marjan Kolarič je namreč še vedno tudi predstavnik kanadskih Slovencev v Svetu Vlade RS za Slovence po svetu, pred tem pa je obe funkciji opravljal sam. Najverjetneje zaradi nove podpredsednice VSKO, Magdalene Symrajh Razpotnik, ki je bila dosedanja leta predsednica SKON Niagara, južnoontarijske krovne organizacije, je toronški VSKO v 2015 po več letih organiziral dobrodelno kosilo za podporo radia Glas in Glasila v Hamiltonu, s čimer je okrepil odnose z južnim Ontariem (Kačičnik 2016a). Podobno smo tako v letu 2014 kot tudi 2015 krovni VSKO vnovič povezali z vsemi slovenskimi organizacijami po Ontariu tudi preko njemu lastnega tiskanega medija, Glasila, ko smo po participativnem modelu iz maloštevilnega uredništva krog dopisnikov razširili na kar 40 dopisnikov za prispevke in fotografije. Ker tovrstna poročanja iz posameznih organizacij običajno pripravljajo predsedniki ali odborniki, lahko ta dejanja narodnega poziva na področju medijev ter drugih političnih premikov zagotovo pripišemo k povišanju ocene za politični status. Pomembno za 
politični status kanadsko-slovenske skupnosti pa je še dejstvo, da je Kanada v letu 2014 po nekaj letih spet dobila slovenskega veleposlanika, Marjana Cencena (Čuš 2014), do takrat pa je to funkcijo opravljala Irena Gril kot pooblaščena ministrica. Prav tako se je povišala ocena ekonomskemu statusu. S 1. januarjem 2016 sta se namreč združili obe slovenski banki v eno, za kar so dogovarjanja in postopki zagotovo tekli že v preučevanem obdobju 2014-2015. Poleg tega je jeseni 2014 v Kanadsko-slovenski gospodarski zbornici nastopil novo izvoljeni odbor s prenovljenim programom, ki po novem spet skrbi za številna srečanja in izobraževalne seminarje slovenskih gospodarstvenikov v Kanadi. Zato smo povišali oceno tudi industriji, ker smo ugotovili, da se slovenska narodna identiteta udejanja tudi z institucionalnim povezovanjem slovenskih podjetij. Jezikovni status znotraj skupnosti v 2014 in 2015 se je prav tako dvignil vsaj za oceno. S svojimi aktivnostmi smo v skupnosti tako $\mathrm{v}$ institucionalnem delovanju kot tudi s pripadniki na terenu izven nje komunicirali v slovenščini, če je bilo to le mogoče glede na predispozicije sogovornikov, in smo jih spodbujali $\mathrm{k}$ rabi slovenskega jezika. Tako tudi v formalnem položaju, ko smo na primer na letnem srečanju predsednikov društev, včlanjenih v VSKO, kljub celotnemu poteku sestanka $\mathrm{v}$ angleškem jeziku poročali o preteklem letu ter načrtih za prihodnje leto za Glasilo v slovenščini. Prav tako smo v Glasilu v letu 2015 uvedli rubriko z nalogami za utrjevanje slovenščine ter držali enakovredno razmerje prispevkov med slovenščino in angleščino. Rabo slovenščine smo spodbujali v interakciji $z$ najrazličnejšimi pripadniki skupnosti na prireditvah in banketih, prav tako pa dvakrat tedensko s številnimi pripadniki v slovenski prodajalni. Ker smo v dejavniku narodnega poziva k rabi slovenščine imeli možnosti za uveljavljanja dejanj za kar najširši obseg, lahko trdimo, da smo v obdobju 2014 in 2015 vitalnost skupnosti na področju rabe jezika zagotovo dvignili vsaj za oceno.

Za institucionalno podporo se je ocena zvišala za eno oceno na več področjih. Pri opazovanju institucionalne podpore $\mathrm{v}$ organizaciji manjšine v obdobju 2014-2015 smo slednjo postavko ocenili za eno višje, ker se je obstoječemu sistemu organizacij v 2015 pridružilo društvo Preskok. Ta je za vitalnost kanadsko-slovenske skupnosti izrednega pomena, saj gre za društvo izven obstoječih okvirjev politične in ekonomske emigracije kanadskih Slovencev. Združuje mlade Slovence, ki prihajajo v Kanado po letu 2008, s tem pa so vpeti v mrežo institucij skupnosti preko pobratenja z društvom Slovenski dom. Novodobni priseljenci se namreč po večini ne vključujejo $\mathrm{v}$ dejavnosti širše kanadsko-slovenske skupnosti oz. se v 
njih udejstvujejo le nekateri, pa še to na večjih letnih prireditvah, organizirajo pa lastna srečanja nekajkrat letno, običajno filmske večere $\mathrm{v}$ centru Toronta. Oceno za področje množičnih občil smo povišali za kar dve oceni zaradi poglobljenega uvida $\mathrm{v}$ terenske razmere, do česar pri pilotskem ocenjevanju še nismo imeli dostopa. Radio Glas kanadskih Slovencev po novem ocenjujemo kot močno in utrjeno institucijo ter medij, ki skrbi za redno udejanjanje narodnega poziva, tako $\mathrm{v}$ obliki glasbe in rabe slovenskega jezika kot tudi poročanja in vpetosti ustaljene uredniške in tehnične ekipe $\mathrm{v}$ skupnost po participativnem modelu, saj oddajo tvorijo tudi pripadniki s čestitkami, oglasi prireditev v skupnosti posameznih društev, urednici pa se tudi redno udejstvujeta vseh prireditev skupnosti. V pilotskem ocenjevanju in predhodnem obisku terena ravno tako še nismo zaznali t. i. newsletterjev, ki so zelo pomembna in aktivna ter zapisana medijska orodja, tako v preteklosti kot tudi v letih v 2014 in 2015. Gre za redne publicistične 4-stranske oblike internega značaja $\mathrm{v}$ angleškem jeziku $\mathrm{z}$ nekaterimi slovenskimi članki, na primer Our Story Kanadsko-slovenskega zgodovinskega društva in Newsletter Krekove banke, ki sta v elektronski obliki nekajkrat letno posredovana seznamu pripadnikov, ki so z njimi kakorkoli povezani. Ponekod se najdejo tudi tiskane verzije, npr. Krekov na lastnih bančnih okencih ter Our Story v obeh župnijah. Prav tako izdaja Novice še slovenski dom za ostarele Lipa. Tedenske tiskane novice izdajata tudi obe slovenski župniji, to sta Vestnik hamiltonske župnije (razposlan tudi elektronsko) in Župnijski list toronške, ki sta večinoma striktno dvojezična in vsebujeta poročila, novice, napovedi, nauke nedeljskih maš ter tudi oglaševanje. Vsebinsko-strukturne in tehnične izboljšave ter občutno povečanje uredništva pa je v tem obdobju zagotovo bilo deležno ravno Glasilo, osrednja publikacija Slovencev v Kanadi, zato oceno vitalnosti na področju množičnih občil za kanadsko-slovensko skupnost v Ontariu ocenjujemo z oceno srednje visoko. Na področju vzgoje in izobraževanja v 2014-2015 ni bilo bistvenih sprememb v institucionalnem delovanju skupnosti, še vedno redno delujejo pevske in folklorne skupine kot pri pilotni oceni, le da se je Slovenski šoli po več letih šolski urnik v šolskem letu 2014/2015 skrajšal za eno uro in da je decembra 2015 prvič v zgodovini slovenske župnije Brezmadežne odpadlo Miklavževanje, ki velja za osrednjo otroško-mladinsko prireditev leta $v$ skupnosti. Slovenska šola $v$ Torontu, ki jo obiskuje sto učencev letno, je v letu 2014 ustanovila Delovno skupino za kurikulum, tako Slovenska šola Toronto kot Slovenska šola Hamilton pa sta novembra 2014 v sodelovanju s Centrom za slovenščino kot drugim/tujim jezikom in 
Uradom Vlade RS za Slovencev v zamejstvu in po svetu organizirali seminar za poučevanje slovenščine kot drugega tujega jezika za izseljenske učiteljice v Kanadi. Tega so do sedaj izvajali le v Ljubljani, torej gre za dogodek enkratnega značaja. Zaradi produkcijsko in recepcijsko učinkovitega načrtovanja pouka jezika in književnosti $v$ dveh šolskih letih 6 . razreda $\mathrm{v}$ Torontu (20 učencev) in vzpostavitve medkulturnega modela učne priprave za pouk jezika in književnosti $\mathrm{z}$ udejanjanjem narodnega poziva za izseljensko prostovoljno šolo, specifično na toronškem primeru, ki bo po končani raziskavi Delovni skupini za kurikulum Slovenske šole Toronto predlagan $\mathrm{v}$ razmislek za univerzalni kurikulum, smo oceno vzgoje in izobraževanja ocenili z oceno višje.

V obdobju 2014-2015 ni bilo bistvenih sprememb na področju administrativnih uslug, industrije in religije, saj gre za področja, kjer se spremembe dogajajo le redko in izredno počasi. Še vedno deluje Informacijski center VSKO ob sobotah kot zadnja leta poprej, prav tako so povsem ustaljene administrativne usluge društev (obveščanje o dogodkih, prodaja vstopnic ipd.) ter cerkvene dejavnosti. Tako je tudi na področju kulture. Za oceno višje smo ocenili še stike $z$ matično domovino. Česar pri pilotski oceni še nismo upoštevali, je, da so stiki s Slovenijo zelo aktivni zaradi slovenskega Veleposlaništva v Ottawi, ki se kljub oddaljenosti od Toronta ( 5 ur severno) in društev v južnem Ontariu redno udejstvuje prireditev v skupnosti ter z njo sodeluje, kjer je to mogoče, tako v letu 2014 kot tudi 2015. Pomembno dejanje okrepljenih stikov $\mathrm{z}$ matično domovino je tudi po več letih obisk ministra za Slovence v zamejstvu in po svetu, Gorazda Žmavca, ki je obiskal skupnost tako v Ontariu kot tudi Vancouvru, Edmontonu, Calgaryju in Winnipegu (Kačičnik 2016b). Čeprav se je to zgodilo spomladi 2016, in ne v preučevanem obdobju 2014-2015, pa se je tega že takrat načrtovalo. S Slovenijo se je povezalo tudi Glasilo, ki je poskrbelo za dopisnika iz Ljubljane, junija 2014 pa se tudi promoviralo na prireditvi Dobrodošli doma ter vzpostavilo sodelovanje $\mathrm{z}$ nekaterimi slovenskimi mediji, npr. radijem Koper in radijem Veseljak, po zaslugi radia Glas, ki vzdržuje redne stike med radijem Glas in slovenskimi mediji prek Marije Ahačič Pollak. V letu 2015 je Slovenijo kolektivno obiskala še Slovenska šola v obliki maturantskega izleta. Zagotovo pa lahko trdimo, da so stiki z matico krepkejši, kot smo predvidevali, tudi $\mathrm{v}$ individualnih in zasebnih obiskih, ki so najbolj pogosti junija oz. v poletnem času, pri nekaterih vsakoletno, pri drugih občasno. V skupnem seštevku smo statusne spremenljivke za obdobje 2014-2015 ocenili za pol ocene višje kot po pilotski oceni vitalnosti, za 
demografske spremenljivke prav tako niti na terenu nismo uspeli pridobiti podatkov za statistično analizo, skupno oceno vitalnosti institucionalne podpore pa smo zvišali za eno oceno.

$\mathrm{V}$ predlaganem pristopu s pomočjo literarnega modela gre torej za dejanja krepitve slovenske narodne identitete $\mathrm{z}$ upoštevanjem participativnega modela. Model materialnih dejavnikov udejanjanja narodnega poziva za izseljensko skupnost zato deluje kot odlično sistematično orodje ali nekakšen daljnogled za opazovanje dejanj aktivnih področij v manjšinski skupnosti, kjer se potencialno uresničuje narodni poziv, urejanje le-teh ali implementiranje dodatnih, kar smo preverili z vnovično ocenitvijo vitalnosti skupnosti po Gilesovi taksonomiji. Pri tem je bilo ključnega pomena dvoletno poglobljeno terensko delo. Tovrstni pristop predlagamo za preučevanje slovenskih skupnosti, tako izseljenskih kot tudi zamejskih ter priseljenskih drugih narodnosti v Sloveniji; prav tako pa manjšinskih primerov vsake druge narodnosti.

\section{Viri}

Muller, Michael in Allison Druin. 2003. "Participatory Design: The Third Space in HCI.« <http://www.watson.ibm.com/cambridge/Technical_Reports/2010/TR2010.10\%20Participatory\%2O Design\% 2 oThe\% 2 oThird\%2oSpace\%2oin \% 2 o HCI.pdf.> (Dostop 29. 4. 2015)

Participatory Design. 2015. <http://en.wikipedia.org/wiki/Participatory_design>. (Dostop 29. 4. 2015)

\section{Literatura}

Čuš, Alenka. 2013. »Družbeni in prostorski vidiki identitete in jezikovne prakse (primer Slovencev v Torontu)«. Seminarsko delo. Koper: Univerza na Primorskem, Fakulteta za humanistične študije.

--- 2014. »Nov Veleposlanik, dr. Marjan Cencen, na delovnem mestu v Ottawi«. V Glasilo kanadskih Slovencev 19 (11): 15-21. Toronto: Vseslovenski kulturni Odbor.

James, William. 2002. Pragmatizem. Ljubljana: Krtina.

Kačičnik, Alenka. 2016a. »Dobrodelno kosilo VSKO Odbora v Hamiltonu«. V Glasilo kanadskih Slovencev 21 (15): 4-5. Toronto: Vseslovenski kulturni Odbor. 
---- 2016b »Minister Gorazd Žmavc na obisku v Kanadi«. V Glasilo kanadskih Slovencev 21 (17): 26-27. Toronto: Vseslovenski kulturni Odbor.

Lešnik, Bogdan. 1997. Subjekt v analizi. Ljubljana: ISH - Fakulteta za podiplomski humanistični študij.

Nećak Luk, Albina idr. 1998. Medetnični odnosi in etnična identiteta $v$ slovenskem etničnem prostoru. I, izsledki projekta. Ljubljana: Inštitut za narodnostna vprašanja.

Potocco, Marcello. 2012. Nacionalni imaginariji. Literarni imaginariji: različice nacionalnega poziva $v$ literaturi in $v$ literarnih kontekstih. Ljubljana: Pedagoški inštitut.

Strle, Urška. 2009. »Slovenci v Kanadi: izseljevanje skozi prizmo življenjskih zgodb «. Doktorska disertacija. Univerza v Ljubljani, Filozofska fakulteta, Oddelek za zgodovino.

Šimenc, Marjan. 2002. "William James, pragmatizem in resnica«. V Pragmatizem. William James: 209-224. 